\title{
Assessment of Health Care Waste Segregation Practice and Associated Factors of Health Care Workers in Gondar University Hospital, North West Ethiopia, 2013
}

\author{
Avier Mesfin ${ }^{1, *}$, Walelegn Worku ${ }^{2}, Z_{\text {Zemichael Gizaw }}^{2}$ \\ ${ }^{1}$ Hygiene and sanitation office, Gondar University Teaching Hospital, Gondar City, Ethiopia \\ ${ }^{2}$ Department of Environmental and Occupational Health and Safety, Institute of Public Health, College of Medicine and Health Sciences, \\ Gondar University, Gondar City, Ethiopia \\ *Corresponding Author: mesfinavier197@gmail.com
}

Copyright (C) 2014 Horizon Research Publishing All rights reserved.

\begin{abstract}
Introduction: Health care wastes are of great importance due to its potential environmental hazards and public health risks. The ineffective handling and segregation of healthcare waste can result additional costs related to the disposal of waste if not segregated appropriately. Objective: To assess health care workers practice and associated factors towards health care waste segregation in Gondar University hospital Gondar, Ethiopia, 2013.Methods: Institutional based cross- sectional study was employed and Study participants were selected by stratified random sampling using profession category. Pretested standardized questionnaire and observational check list were used. Result: This study showed that $173(46.3 \%)$ of the respondents had correctly practiced health care waste segregation. Being a nurse profession $(\mathrm{AOR}=0.27 ; 95 \% \mathrm{CI}=0.15-0.51)$, working more than eight hours ( $\mathrm{AOR}=0.28 ; 95 \% \mathrm{CI}=0.17-0.47)$ and unavailability of color coded containers (AOR $=0.18 ; 95 \%$ $\mathrm{CI}=0.08-0.38$ ) were factors influencing the practice of health care waste segregation. Conclusion: This study showed that health care workers practice towards segregation of health care waste in university of Gondar hospital is poor. Profession, working hours in a day and availability of color coded containers were factors that affect the health care waste segregation practice.
\end{abstract}

Keywords Health Care Wastes, Waste Segregation, Practice, Health Care Workers, Gondar University Hospital

\section{Introduction}

Healthcare activities lead to the production of health care waste that may lead to adverse health outcome. Hospitals must be considered unique places compared to a 'normal' home environment, because it can cause a risk of potential infection. A health care worker that produces waste as part of their job is a 'waste producer' (1).

Health care wastes are of great importance due to its potential environmental hazards and public health risks. World Health Organization (WHO) has advocated health care wastes as special wastes and it is now commonly acknowledged that certain categories of health care wastes are among the most hazardous and potentially dangerous of all wastes arising in communities, as exposure to hazardous health care waste can result in disease or injury (2). Pathogens and toxic chemicals in health care waste can pose serious health risks for waste collectors, patients and health care workers, among these health risks HIV/AIDS, viral hepatitis B (HBV) and hepatitis C (HCV). HIV, HCV and HBV have the risk of transmission $0.3 \%, 1.8 \%$ and $30 \%$, respectively from one sharp injury $(3,4)$.

There is no proper segregation as general waste and sharps. Health care wastes were observed mixed in common collection vessels. Despite the availability of enough bins in some health facilities color coding practices were poor. Proper segregation of health care waste produced during health care must follow the standardized procedures, according to national guidelines. It is important to segregate waste because it fosters the reduction of risks to healthcare workers, and enhances cost control for hazardous waste disposal by decreasing treatment costs $(2,5-7)$.

Health care waste poses a serious threat to the environmental health without comprehensive guidelines and efficient management as it contains highly toxic chemicals, pathogenic viruses and bacteria. Regarding infection a contaminated needle which is handling improperly had the risk of infection one in three for hepatitis $\mathrm{B}$, one in 30 for hepatitis $\mathrm{C}$ one in 300 for HIV (8). The principal opportunity for the general public to contact health care waste could occur from health care waste generated in the health care facilities which are improperly discarded equipments (7).

In Ethiopia, as in many developing countries, health care workers practice towards health care waste segregation has not got sufficient attention. There is not sufficient recorded 
information on health care waste management and technologies and this hinders the planning for better management of waste. The main problem of waste management in Ethiopia include lack of appropriate segregation between hazardous waste and non hazardous waste, the absence of proper waste disposal, insufficient training of health care workers, inadequate personal protective equipment and overall improper management strategies in the handling and disposal activities of waste $(9,10)$. Segregation is especially important in developing countries because open dumping is more commonly used. Mixed medical wastes containing sharps and fluids could present a risk of injury and infection to scavengers or children playing around waste sites (5).

Therefore the aim of this study is to evaluate and assess the present health care waste segregation practices among health care providers in Gondar university hospital and determine the associated factors which are related to it.

\section{Objectives of the Study}

\section{General objective}

To assess health care worker's practice and associated factors of health care waste segregation in Gondar University hospital Gondar, Ethiopia, 2013.

\section{Specific objectives}

$>$ To determine the magnitude of health care workers practice towards medical waste segregation in Gondar university hospital.

$>$ To identify associated factors related to health care waste segregation practice among health care workers in Gondar university hospital.

\section{Methods and Materials}

\section{Study design}

An institutional based cross-sectional study was conducted to assess practice and associated factors of health care waste segregation among health care workers in Gondar university hospital.

\section{Source population and study population}

All health care workers working in Gondar university hospital are the source and study populations.

\section{Sample size determination and sampling procedures}

Sample size was determined using the formula for a single population proportion and considering that proportion of practicing health care waste segregation is $33 \%$, (assuming a research done in the management of health care waste in Hawassa city, showed that the proportion of practicing health care waste segregation is $33 \%$,) and $95 \%$ level of confidence and 5\% margin of error. Therefore, the sample size was determined as follows:

$$
n=\frac{(z \alpha / 2)^{2} p q}{W^{2}}
$$

$\mathrm{n}=$ the sample size to estimate a single population proportion

$\boldsymbol{z} \boldsymbol{\alpha} / \mathbf{2})=$ Standard score corresponding $95 \%$ of certainty (1.96)

$\mathrm{p}=$ proportion ( this is taken from Hawssa on health care waste management research)

$$
\begin{gathered}
\mathrm{W}=0.05 \text { (absolute precision) } \\
\mathrm{n}=(1.96)^{2} 0.33(1-0.33) /(0.05)^{2}=340
\end{gathered}
$$

Considering $10 \%$ non response rate (to compensate the study subjects who are not responding), the final sample size was 374 .

\section{Sampling procedure}

Sampling frame consisting of all health care workers in the hospital was obtained. According to their professional category proportionate stratified random sampling technique was administered. To identify the study subjects from each strata simple random sampling was used.

\section{Data collection procedure}

Data were collected using structured and pre-tested questionnaire and observational checklist which was developed based on the related studies. Data collection was administered by data collectors. A self administered questionnaire was employed by data collectors to the selected health care providers to collect the data. Observational checklist was used to assess the practice in terms of segregation. During observation, when the study subjects were doing their task by asking the consent from ward heads, health care providers and patients. The observation was carried out first using observational checklist and then self administered questionnaire was given for the study subjects.

\section{Data quality assurance}

The questionnaire was pre-tested to identify potential problem areas with any of the questions in 19 respondents having similar characteristics with the study subjects nearby Gondar town debark hospital. Training of data collectors and supervisors and pre-testing of the questionnaire were made to ensure the quality of data. Principal investigator and supervisors made spot checking and reviewing the completed questionnaires on a daily basis to ensure completeness and consistency of the information collected.

\section{Study variables}

Dependent variable: Practice on health care waste segregation.

\section{Independent variables:}

- Socio demographic variables: Age, profession category, level of education and work experience.

* Behavioral factors: awareness of disease transmitted by improper medical waste segregation, 
attitude and use of personal protective equipment (PPE).

* Work environment: length of working hours (per day), existence of safety guidelines, availability of color coded containers, rules and regulation, existence of control measure,working department and training.

\section{Data processing and analysis}

Data were entered, coded and cleaned using EPI INFO version 2002 statistical software and then exported to SPSS version 20.0 for further analysis. Descriptive statistics of the collected data was done for most variables in the study using statistical parameters: mean, percentage. Bivariate analysis was used primarily to check which variables have an association with the dependent variable individually. Variables found to have an association with the dependent variables would then be entered into multiple logistic regression for controlling the possible effect of confounders and final the variables which have significant association were identified on the basis of OR, with $95 \% \mathrm{CI}$ and $\mathrm{P}$-value. Hosmer and Lemshow test was used to fit the final regression model (0.638).

\section{Ethical considerations}

Ethical clearance was obtained from the Institutional
Review Board of University of Gondar, Institute of Public Health. Verbal consent from the head of each ward and study participants and patients was obtained. The data collectors were clearly explain the aims of the study. Information was collected after obtaining verbal consent from study participants and each ward head. Respondents were also informed that they can refuse or discontinue participation at any time they want and the chance to ask any thing about the study. Information was recorded anonymously and confidentiality was assured throughout the study period.

\section{Results and Discussion}

\section{Results}

Socio demographic characteristics

A total of 374 health care workers were included in this study and the response rate is $100 \%$. Out of them $251(67.1 \%)$ were male and $123(32.9 \%)$ were female. The mean age of the respondents was $28 \pm 5$ year. Among the respondents 242 (64.7\%) were single and most of the respondents were nurses in profession category, i.e. $214(57.2 \%)$. From the total respondents $291(77.8 \%)$ had a degree. Regarding experience of the respondents $172(46 \%)$ had below five experience years (see Table 1).

Table 1, Socio demographic characteristics of the respondents in Gondar university hospital Gondar town, Northwest Ethiopia, May 2013

\begin{tabular}{|c|c|c|c|}
\hline Variables & Variable category & $\mathbf{N}$ & Frequency( \%) \\
\hline Sex of the respondents & $\begin{array}{l}\text { Male } \\
\text { Female }\end{array}$ & $\begin{array}{l}251 \\
123\end{array}$ & $\begin{array}{c}67.1 \\
32.9\end{array}$ \\
\hline Age of the respondents & $\begin{array}{c}\text { 20-25 years } \\
26-30 \text { years } \\
31-35 \text { years } \\
\text { Above } 36 \text { years }\end{array}$ & $\begin{array}{l}146 \\
93 \\
106 \\
29\end{array}$ & $\begin{array}{r}39 \\
24.9 \\
28.3 \\
7.8\end{array}$ \\
\hline Marital status & $\begin{array}{l}\text { Single } \\
\text { Married }\end{array}$ & $\begin{array}{l}242 \\
132\end{array}$ & $\begin{array}{l}64.7 \\
35.3\end{array}$ \\
\hline Level of education & $\begin{array}{c}\text { Diploma } \\
\text { Degree Specialty in different course }\end{array}$ & $\begin{array}{l}51 \\
291 \\
32\end{array}$ & $\begin{array}{l}3.4 \\
7.8 \\
8.6\end{array}$ \\
\hline Profession type & $\begin{array}{l}\text { Medical doctors } \\
\text { Nurses } \\
\text { Laboratory technologists } \\
\text { Others }\end{array}$ & $\begin{array}{l}90 \\
214 \\
50 \\
20\end{array}$ & $\begin{array}{l}24.1 \\
57.2 \\
13.4 \\
5.3\end{array}$ \\
\hline Experience in years & $\begin{array}{l}\text { Below five years } \\
6-10 \text { years } \\
11-15 \text { years } \\
\text { Above } 16 \text { years }\end{array}$ & $\begin{array}{l}172 \\
137 \\
35 \\
30\end{array}$ & $\begin{array}{c}48.9 \\
36.6 \\
9.4 \\
8\end{array}$ \\
\hline
\end{tabular}


Table 2. Working environment characteristics of the respondents in Gondar university hospital Gondar town, Northwest Ethiopia, May 2013

\begin{tabular}{|c|c|c|c|}
\hline Variable & $\begin{array}{l}\text { Variable } \\
\text { category }\end{array}$ & $\mathbf{N}$ & Frequency \%) \\
\hline \multirow{2}{*}{ Waste management system } & Yes & 284 & $75.9 \%$ \\
\hline & No & 90 & $24.1 \%$ \\
\hline \multirow{2}{*}{ Health care waste segregation component } & Yes & 310 & $82.9 \%$ \\
\hline & No & 64 & $17.1 \%$ \\
\hline \multirow{4}{*}{$\begin{array}{l}\text { Availability of different color coded containers } \\
\text { Awareness of rules and regulation }\end{array}$} & yes & 298 & $79.7 \%$ \\
\hline & No & 76 & $20.3 \%$ \\
\hline & Yes & 180 & $48.1 \%$ \\
\hline & No & 194 & $51.9 \%$ \\
\hline \multirow{2}{*}{ Clearly defined procedures for handling segregation } & Yes & 199 & $53.2 \%$ \\
\hline & No & 175 & $46.8 \%$ \\
\hline \multirow{2}{*}{ Control measure for segregation } & Yes & 185 & $49.5 \%$ \\
\hline & No & 189 & $50.5 \%$ \\
\hline \multirow{2}{*}{$\begin{array}{l}\text { Provision of annual education on health care waste } \\
\text { management by the hospital }\end{array}$} & Yes & 20 & $5.3 \%$ \\
\hline & no & 354 & $94.7 \%$ \\
\hline Working hours in a day & $\begin{array}{c}\text { Eight hours } \\
\text { More than eight } \\
\text { hours }\end{array}$ & $\begin{array}{l}205 \\
169 \\
\end{array}$ & $\begin{array}{l}54.8 \% \\
45.2 \% \\
\end{array}$ \\
\hline
\end{tabular}

\section{Working environment characteristics}

There is 24 working department in the hospital. Out of the total respondents $284(75.9 \%)$ and $310(82.9 \%)$ were described that there is waste management system and medical waste segregation component in their health care setting, respectively. $298(79.7 \%)$ of the respondents had color coded containers in the working department.

Among the total respondents 205 (54.8\%) worked eight hours in a day. Regarding waste management responsibilities, $191(51.1 \%)$ of the respondents had no responsibilities included in their job description. 194 (51.9\%) were also did not aware about rules and regulation in health care waste segregation in the hospital.

Among the total respondents, 199 (53.2\%) had clearly defined procedures for segregation and handling health care waste, but with regard to control measure $189(50.5 \%)$ of the respondents described that there is no control measure mechanism for segregation and handling of health care waste.

Out of the total $293(78.3 \%)$ and $354(94.7 \%)$ of the respondents revealed, there is no any training program on health care waste management system in past 12 months and the hospital did not provide annual education on waste management system for employee, respectively (see Table 2).

\section{Behavioural characteristics}

Knowledge on health care waste segregation

Out of the total respondents $206(55.1 \%)$ were knowledgeable i.e. who respond above the mean score $\geq 13$ of which $25.1 \%$ practiced correctly and $30 \%$ of the respondents practiced incorrectly. Among the respondents who agreed with that major classification of medical waste as infectious and non infectious were $178(47.6 \%)$ and 254 $(67.9 \%)$ of the respondents revealed and agreed medical waste constituent is only infectious medical waste. Regarding identification, When medical wastes mixed in to some general waste, $234(62.6 \%)$ of the respondents considered this waste as health care waste. Out of the total respondents $56.7 \%$ can color code the health care waste. Of which $40.6 \%$ were correctly match the health care wastes with the color coded containers.

\section{Attitude on health care waste segregation}

Regarding attitude towards health care waste segregation practice $283(75.7 \%)$ of the respondents had positive attitude i.e. who respond above the mean score $\geq 9$ of which $35.3 \%$ of the respondents practiced correctly and $40.4 \%$ practiced segregation incorrectly. Out of the total respondents, 175 (46.8\%) used PPE (personal protective equipment) when 
they are handling infectious health care wastes (see Table 3 ).

\section{Practice towards health care waste segregation}

During observation, all of the respondents segregated any waste from the waste stream among these 173 (46.3\%) practiced health care waste segregation correctly and 201 (53.7\%) practiced incorrectly. Out of the total respondents $275(73.5 \%)$ segregated infectious health care waste from the general waste stream. $370(98.9 \%)$ of the respondents used plastic containers and carton safety box to segregate health care waste. Only $25.4 \%$ of the respondents used containers with biohazard symbol labeled for infectious health care waste. Regarding health care waste containers, 322 (86.1\%) of the health care workers used containers which are daily emptied.

Table 3. vioural characteristics of the respondents in Gondar university hospital Gondar town, Northwest Ethiopia, May 2013.

\begin{tabular}{|c|c|c|}
\hline Variables & $\mathbf{N}$ & Frequency $(\%)$ \\
\hline \multicolumn{3}{|l|}{ Major classification of health care wastes } \\
\hline Chemical and toxic & 57 & 15.2 \\
\hline Infectious and noninfectious & 178 & 47.6 \\
\hline Pathological and pharmaceutical & 53 & 14.2 \\
\hline Biological and sharps & 86 & 23 \\
\hline \multicolumn{3}{|l|}{ Constituents of health care waste } \\
\hline Infectious & 254 & 67.9 \\
\hline $\begin{array}{c}\text { Non infectious } \\
\text { Both infectious and non infectious }\end{array}$ & $\begin{array}{c}7 \\
113\end{array}$ & $\begin{array}{c}1.9 \\
30.2\end{array}$ \\
\hline \multicolumn{3}{|c|}{$\begin{array}{l}\text { Mixing general waste with health care waste, considering the } \\
\text { whole waste }\end{array}$} \\
\hline General waste & 140 & 37.4 \\
\hline Health care waste & 234 & 62.6 \\
\hline \multicolumn{3}{|l|}{ Color coding the health care waste } \\
\hline Yes & 212 & 56.7 \\
\hline No & 162 & 43.3 \\
\hline \multicolumn{3}{|l|}{ Matching the health care wastes and containers } \\
\hline correctly match the answer & 152 & 40.6 \\
\hline incorrectly match the answer & 60 & 16 \\
\hline \multicolumn{3}{|l|}{ PPE usage for } \\
\hline Infectious & 175 & 46.8 \\
\hline Non infectious & 27 & 7.2 \\
\hline Both infectious and non infectious & 134 & 35.8 \\
\hline Do not use & 38 & 10.2 \\
\hline
\end{tabular}




\section{Multivariate analysis showing association of variables with practice of health care waste segregation (see Table 4):}

Table 4. Association of variables with practice on health care waste segregation of health care workers in Gondar university hospital Gondar, Gondar town, Northwest Ethiopia May, 2013

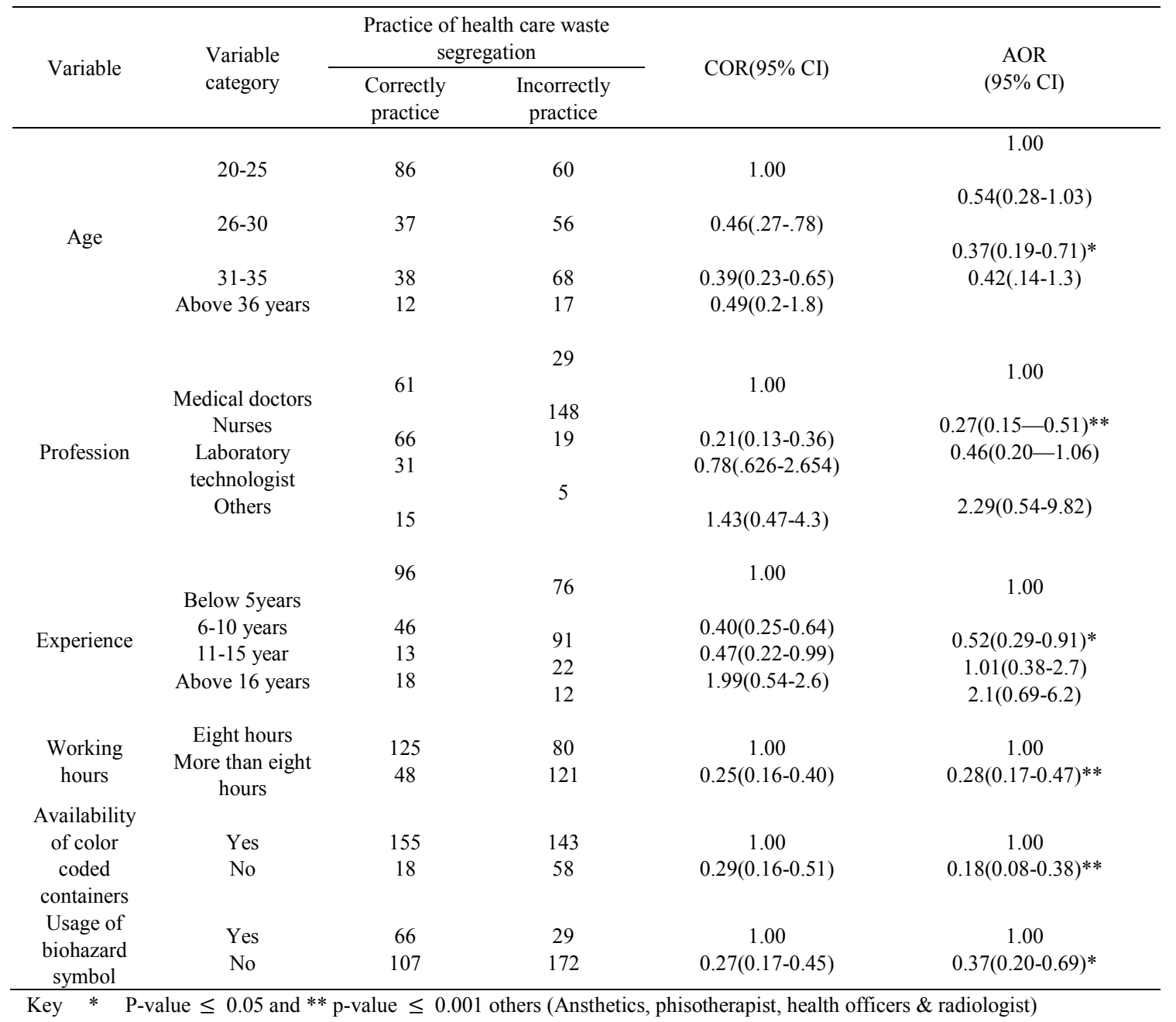

\section{Discussion}

Handling health care waste is crucial issue since this is a potential hazard affecting the health of clients, health care workers, the community and the environment. Practice towards health care waste segregation was assessed by observation. All of the respondents segregate health care waste from the general waste stream of which173 (46.3\%) practiced health care waste segregation correctly and 201 (53.7\%) practiced incorrectly. It might be due to different reasons: lack of availability of color coded containers in all wards and unavailability of containers labeled with biohazard symbol for infectious health care waste. The study done in Hawssa city revealed that there is segregation in 33\% of health facilities, which is lower than this study.

Age, profession type, experience, working hours, availability of color coded containers, and usage of biohazard symbol for infectious medical waste were factors identified as factors towards proper health care waste segregation practice.

This study found age as a factor for practicing health care waste segregation properly, out of the total respondents who are in the age group of 31-35 were $63 \%$ less likely to be correctly practice the segregation compared to the respondents who are in the age group of 20-25. In contrast, a study conducted in UK revealed that all of the professions that were careless in the practice of segregation were either in the age group of $16-20$ or $20-30$ (11). It might be respondents who are in the older age group relative with the other age categories put health care waste in a wrong bin, because there is ignorance and tiredness of health care workers to put health care wastes in appropriate bin.

Work experience also has an effect on the practice of health care waste segregation. The respondents who have experience years $6-10$ were $48 \%$ less likely to be correctly practice segregation of health care waste compared to the respondents who have $\leq 5$ experience years. The respondents who have below five experience years may respect rules and regulation and doing their tasks accordingly and they want to know more and practice than the other former health care workers.

This study indicates nurses were $73 \%$ less likely to be correctly practice health care waste segregation compared to 
medical doctors. In contrast a study in Bangalore (India) found that the nurses practiced HCWM better than the other staffs and a significant difference was found $(\mathrm{P}<0.001)$ (12). In this study set up, it may be due to that nurses have more work burden and contact with many patients than the other staffs, this leads to practice the segregation improperly, they may be forget the procedures for health care waste segregation.

Working hours has its own effect on segregation. The respondents who work more than eight hours in a day were $72 \%$ less likely to be correctly practice health care waste segregation compared to the respondents who work eight hours in a day. It might be due to tiredness, if the health care worker worked more than the recommended hours it leads to practice improperly.

The respondents who have no color coded containers in the working department were $82 \%$ less likely to be correctly practice health care waste segregation than who do have color coded container in the working department. This is in line with a study done in Addis Ababa that all hospitals were found to be collected and transported in perforated plastic bins (13). This might be if there is availability of color coded containers in the working department, it leads for better practice of health care waste segregation.

The respondents who are not using containers with the biohazard symbol were $63 \%$ less likely to be correctly practice health care waste segregation compared to the respondents who are using the containers with the biohazard symbol labeled for infectious health care wastes. This is consistent with a study In Tanzania and southern Africa, the hospitals did not label infectious health care waste with bio hazard symbol and this resulted in poor health care waste management $(7,14)$. This might be due to lack of descriptions or symbols on waste containers and these results in poor segregation practice, because health care waste containers were not labeled. The health care workers are obligated to put health care wastes in wrong bins.

\section{Conclusions}

This study showed that health care workers practice towards segregation of health care waste in University of Gondar hospital is poor. Age, profession, experience year, working hours in a day, availability of color coded containers, and usage of containers with biohazard symbol labeled for infectious health care waste were factors that affect the health care waste segregation practice.

\section{REFERENCES}

[1] Liza E, Kim S, Rose G, Stephen B. Essential practice for infection prevention and control guidance for nursing staff. UK; Royal college of nursing, 20 Cavendish square, London W1G 0RN; 2012

[2] Vera F. and Margardiariabu T. Assessing the medical waste management practices and associated risk perception in Algarve hospital Portugal.2010.

[3] Jundihaibulah K. Managing the health care solid waste in selected districts of Punjab Pakistan.2010, 26 (4): 795-04.

[4] World Health Organization. Management of waste from injection activities at the district level: guidelines for district health managers. Geneva, Switzerland: World Health Organization; 2006.

[5] Qaesar S. Survey of sharp waste disposal system in clinics of New Karachi Pakistan.WHO reports. 2008.

[6] Taghipour H. and Mosafri M. The challenges of a medical waste management: A case study in northwest Iran-Tabriz.2009, 27 (4): 328-35.

[7] Mayele S. and Lysenga T. Factors affecting medical waste management in low level health facilities in Tanzania. African journal of environmental science and technology; 2010, 4 (5): 304-318.

[8] Kim S. And Rose G. prevention of sharps injuries in the health care sector UK; Royal college of nursing, 20 cavendish square, London W1G 0RN; 2010.

[9] Azage M. Assessment of healthcare waste generation rate \& its management system in health centers of West Gojjam zone, Amhara Region: A Master's thesis. Addis Ababa, Ethiopia: Addis Ababa University, Faculty of Medicine, Department of Community Health; 2007. Pub Med Abstract Publisher Full Text

[10] Hayilmichael D,Davy A, Yirsaw D, Zegeye A. Assessing the management of health care waste in Hawssa City Ethiopia. August 42010.

[11] Pudussery K. A study on the medical waste management at the Norfolk and Norwich university hospital UK.2011

[12] Suwaran M. and Ramesh G. Study about awreness and practices about health care waste management among hospitals staff in a medical college hospital Banglore. February 2013.

[13] Kote M, Alemu K, Gizaw A, Mehammed Z. Assessment of the health care waste generation rates and its management system in hospitals of Addis Abeba Ethiopia. BMC publication. 2011.

[14] Aseweh P. Medical waste management practices in a southern African hospital. Journal applied science and environmental management.2007, 11(3):91-96 